\title{
ACRL in Orlando \\ ACRL programs at the ALA Annual Conference
}

\begin{abstract}
A
LA's 135th Annual Conference was held June 23-28, 2016, in Orlando. Approximately 16,597 librarians, library support staff, exhibitors, writers, educators, publishers, and special guests attended the conference. $E d$. note: Thanks to the ACRL members who summarized programs to make this report possible.
\end{abstract}

\section{Strategies and partnerships}

"Strategies and Partnerships: Tailoring Data Services for Your Institutional Needs" was the title of this year's ACRL President's Program.

Understanding how to effectively discover and use data is important. Library data services require coordinated communication and collaboration across units to enhance the knowledge and awareness of data literacy.

The desired outcome of successful library data services-according to Yasmeen Shorish (James Madison University), Kristin Partlo (Carleton College), and Sara Bowman (Center for Open Science) - transcends the instruction in the methodologies for discovery, management, and curation of data to build strategic partnerships that engage in identifying campus needs and mapping novel services.

A strategic and proactive approach to data services is critical. Shorish favors establishing a common understanding among stakeholders and for meeting people where they are. To accomplish this, libraries carefully use the existing data to develop strategies for collaborative data-driven research. These efforts can be frustrating because of the emergent and challenging area of engagement, but can also lead to an evolution of services and new job roles such as data visualization librarian.

By acknowledging that data services can take many forms, Partlo stressed an importance of focusing on local institutions to find the right fit. At her college, efforts are being made to evaluate gaps in existing services to identify cross-disciplinary needs, such as the need for a repository. The message that she and the presenters' handout tried to convey was the encouragement to leverage existing resources to jumpstart novel projects.

Another way to harness data assets is by building a reputation for excellence beyond institutional boundaries. Bowman outlined a partnership option to improve openness and reproducibility of research. Open Science Framework, developed by the nonprofit Center for Open Science, integrates daily workflows to archive and share data. This is a fresh approach to nudge researchers toward more openness as the library and academia is prodigiously embracing the open educational resources._Joe Mocnik, Georgia College \& State University, joe.mocnik@gcsu.edu

\section{Magical digital encounters of the Social Science kind}

Digital scholarship is rapidly evolving, and many research centers encompass both digital humanities and digital social sciences. The Anthropology and Sociology Section cosponsored "Magical Digital Encounters of the Social Science Kind" with the Women and Gender Studies Section and the Digital Humanities Interest Group. Two presenters, 
Michael Simeone (Arizona State University) and Kathy Weimer (Rice University), shared how digital scholarship, the social sciences, and academic libraries intersect.

Simeone discussed what he stated are three trends that matter to researchers: texts, networks, and people. Researchers often approach him without a hypothesis. They have mountains of data they want to explore-to visualize and see connections, trends, and networks. The visualization, says Simeone, provides people with "multiple ways into the data." When managing digital projects, Simeone advocated for creating partnerships and "connecting expertise."

Weimer spoke on "Place, Space, and Geography in Digital Scholarship," challenging the audience to "think about space in scholarship." She called for spacial literacy in library instruction, and for the library to take advantage of its central location to connect digital tools with researcher needs. Weimer also discussed the initiative at the GeoHumanities Special Interest Group to develop protocols for a peer review process for digital scholarship.

As a way for librarians to get more involved in digital scholarship, Simeone recommends going to an intensive, hands-on institute such as THATCamp or HILT, and then joining a project as a partner. Weimer said to be an observer and "get into the discipline." She suggests going to nonlibrary conferences, attending faculty colloquiums, and seeing what faculty are exploring and want to understand. Finally, both stated that everything digital is collaborative and to partner with others who know more.-Daniel "Brew" Schoonover, Florida State University, dschoonover@fsu.edu

\section{Academic libraries and OER}

ACRL's Community and Junior College Libraries Section sponsored a program entitled "Academic Libraries and Open Educational Resources: Developing Partnerships." The panelists were moderator Robert Kelly (Hutchinson Community College), Heather Blicher (Northern Virginia Community Col- lege), Jeremy Smith (University of Massachusetts-Amherst), and John Schoppert (Columbia Gorge Community College).

The program began with an audience survey, powered by Kahoot. Most of the audience members were eager to learn more about Open Educational Resources (OER).

The panelists began with an overview of OER, including definitions and major motivations behind the OER movement. Smith discussed a survey that was done at the University of Massachusetts that revealed the choices that students are making when confronted with the high cost of textbooks.

Blicher helped the audience understand how librarians can impact the growing OER movement. Librarians can provide information, locate OER materials that can be adapted, create and manage content, and help with copyright issues.

All three panelists provided overviews of successful OER initiatives at their institutions. Schoppert made the important point that "Talk isn't cheap, it takes time." Librarians can be resources to their institutions, helping "build a brand" (marketing OER classes to students).

The major challenges of OER include bookstore pushback; the extraordinary amount of energy that it takes to persuade faculty to take part in the OER revolution; reaching beyond the easy converts as OER matures; a lack of a central directory of OER resources; sustainability; and how to continue to pay faculty to produce OER materials.

Panelists concluded with a consideration of OER assessment.-Robin Brown, Borough of Manhattan Community College, rbrown@ bmcc.cuny.edu

\section{A spectrum of digital initiatives}

The Digital Humanities (DH) Interest Group hosted its first Annual Conference program titled "A Spectrum of Digital Initiatives: Project and Pedagogical Collaborations in Digital Humanities." More than 140 attendees packed the room to learn how librarians can collaborate on digital humanities initiatives ranging from local and regional to international projects. 
Moderator Harriett Green (University of Illinois at Urbana-Champaign) introduced the featured panel of speakers from southeastern U.S. institutions, whose work notably highlighted the rich opportunities for regional digital scholarship activities.

Laurie N. Taylor (University of Florida) presented "Digital Humanities is Always Public Humanities at the University of Florida," in which she highlighted the University of Florida's experiences as a partner in the Digital Library of the Caribbean, and she discussed their library-scholar collaborations that draw upon library collections to build innovative new resources, as well as to integrate libraries and $\mathrm{DH}$ into the classroom.

Emma Annette Wilson (University of Alabama) presented on the initiatives underway at the Alabama Digital Humanities Center, including outreach initiatives, digital pedagogy projects, and large-scale digital research projects that involved campus and interinstitutional collaborations.

Barbara Lewis (University of South Florida Libraries) presented "Multimedia Transformation: Libraries as Resources for Digital Storytelling Tools," discussing multimedia tools for incorporating digital storytelling in research papers and projects, and how to partner with faculty to transform existing assignments into high-quality digital alternatives for students.

The ensuing discussion focused on strategies for building digital scholarship services and campus partnerships. The program ultimately offered a valuable opportunity for librarians to exchange ideas and learn from other practitioners how to engage in the emergent area of digital humanities and librarianship.-Harriett Green, University of Illinois at Urbana-Champaign, green19@illinois.edu

\section{Starting from scratch}

The ACRL Digital Scholarship Centers Interest Group invited several speakers to reflect on ways that libraries can support digital scholarship on their campuses. In "Starting from Scratch: Build Your Digital Scholarship Center Program," speakers underlined the importance of seeking out existing expertise when starting new programs. They also indicated that large and small schools can all create successful programs, given adequate communication internally and externally.

Christina Bell (Bates College), Eric Johnson (Virginia Commonwealth University), and Pamela Price-Mitchem (Appalachian State University) spoke to a common theme in developing digital scholarship programsnamely, that libraries rarely have to build entirely from scratch. Bell explained that her library surveyed the Bates College campus and concluded that 2,000 square feet of space have already been dedicated to digital scholarship activity. With little funding in hand, the organizing task force thus devoted itself to creating a space online to support this existing activity. "The main goal was communicating what we can do," Bell said. Johnson and Price-Mitchem similarly described how their programs grew as experts in data, copyright, and media moved into new teams and departments.

All three speakers emphasized the importance of communication when organizing new programs. For Appalachian State University, internal communication posed early challenges. Price-Mitchem noted that the team at inception had no clear leader or avenue for communicating with external groups like campus IT. In time, these problems were corrected by identifying specific goals, workflows, and liaison duties. Johnson described a separate communication challenge, pointing to the importance of establishing a clear mission for the digital scholarship program. At Virginia Commonwealth University-an arts-oriented school-the new digital scholarship program opted to focus on nontextual tools and media.

A theme across speakers was that every digital scholarship program will look different and that each is worth developing regardless of size and focus.-Talea Anderson, Washington State University, talea.anderson@wsu.edu

\section{Connecting individuals with social services}

A panel of student service providers from 
Orlando-area higher education institutions joined librarians to foster a discussion, sponsored by ACRL, on "Connecting Individuals With Social Services: The Academic Library's Role." Samantha Hines (Missoula College) moderated the panel and the discussion following. The idea for the panel grew out of her research into ways to help boost student retention at her community college campus.

The panel began with Sara Zettervall (Hennepin County Library) discussing “whole-person librarianship,' which explores the connections between librarianship and social work. Her slides can be found at https://mlismsw.files.wordpress. com/2016/07/wpl-2016-final.pdf along with her blog addressing the concept.

Tanisha Carter (Valencia College) spoke about her work as the director of the Bridges to Success program, which provides access to support services for students who need assistance in getting through college, are facing issues of first-generation college students, have financial need, have disability status, experience language and residency barriers, and so on. Carter's presentation about her work helped librarians in attendance better understand what programs like this do and see areas where we can connect or share resources.

Dennis Ferarro (Keiser UniversityOrlando) also helps connect students with resources to overcome barriers to success. He discussed his perspective on a smaller campus with fewer resources, working to connect with providers in the community. $\mathrm{He}$ and the other panelists helped clarify the connection between whole-person librarianship and higher education's growing concern for the "whole student."

Mari Milenkovic (University of Central Florida [UCF]) spoke about her work with the library at UCF, connecting students with information about nutrition and safer sex through wellness initiatives. She provided the audience with practical ideas on how they could, and perhaps already did, work to connect students on their campuses with social service resources.-Samantha Hines,
Missoula College, University of Montana, samantha.hines@umontana.edu

\section{Heroes or villains?}

Assessment can be intimidating, so the panelists of "Expanding Your Assessment Toolbox: Creative Assessment Design for the Novice Instruction Librarian" introduced the topic by discussing villains from Disney movies. The comparison was apt. Instruction librarians might want to control assessment like Ursula wants to control the entire sea. Or they might only see the feedback that they want to see, like the wicked queen in Snow White looking into her Magic Mirror.

The panelists used this entertaining introduction to launch into an earnest look at the purpose and the practice of assessment. Brandon West (SUNY-Geneseo) suggested that librarians may be doing more assessment than they realize by gathering informal feedback from class discussions or by examining their use of technology tools, such as Google Docs and Twitter, to engage their students in learning. Michelle Costello (SUNY-Geneseo) described her assessment activities and outcomes in a course where she was embedded and co-taught class sessions. She used an action research approach to determine if an embedded librarian affected the quality and quantity of students' research efforts outside of class. Finally, Kim Hoffman (University of Rochester) discussed the various types of strategies, tools, and data associated with assessment - summative and formative assessment, qualitative and quantitative data, and high-tech versus low-tech delivery options.

Throughout the session, the panelists encouraged the 150 panel attendees to practice active listening by taking notes and reflecting on what was being addressed. They also integrated exercises into their presentationaudience members developed an assessment strategy, discussed their plans with fellow attendees, and shared their ideas with the crowd. Overall, these exercises provided an excellent opportunity for listeners to actively engage with the materials and to begin planning their own assessment strategies. It also 
helped participants to hear expert feedback about their ideas from the panelists._-Justin de la Cruz, Atlanta University Center Robert W. Woodruff Library, jcruz@auctr.edu

\section{Co-teaching shared threshold concepts}

Brittney Johnson and Moriah McCracken (both of St. Edward's University) discussed their approach for integrating and co-teaching shared threshold concepts of information literacy and writing studies in their ACRL session, "Framing Out New Partnerships: Redesigning Library Instruction and First-Year Writing Programs through Shared Understandings."

Johnson and McCracken described a multisession approach of information literacy instruction that they implemented in a first-semester, first-year writing course at St. Edward's as part of an institutional review board-approved research project. The project aimed to explore what happens when a librarian and instructor co-teach shared threshold concepts in an embedded, integrated multisession instructional model. Students in one section of the course received the multisession approach, while students in a second section of the course served as the "control" group and only received the traditional, one-shot instructional session.

These sessions focused on the concept of scholarship as conversation, one of the six frames in ACRL's Framework for Information Literacy for Higher Education, and overlapping threshold concepts in writing studies, as articulated in Naming What We Know by Linda Adler-Kassner and Elizabeth Wardle. Johnson and McCracken discussed how the scaffolded sessions-which focused on helping students first build a conceptual understanding of scholarship as conversation and then develop strategies for listening to, engaging in, and eventually contributing to a relevant conversation regarding their research project-impacted student learning by sharing reflective writing data for three students (two from the test group, and one from the control group).

Johnson and McCracken concluded by as- serting that assessing students' understanding of threshold concepts is a complex endeavor, and reflective writing is one way to garner insight into students' progress in understanding troublesome concepts.-Brittney Johnson, St. Edward's University, bjohnso1@stedwards. edu

\section{Joyous paranoia}

Andy Spackman began his presentation, "Joyous Paranoia: How Libraries Misunderstand and Mismanage Disruptive Innovation," by asking attendees whether they were tired of debates on the relevance of libraries, but still found themselves morbidly drawn to them. Almost every hand went up.

Librarians both love and hate change. Every trending innovation gets hyped as "disruptive," but the theory of disruptive innovation describes only a specific type. Drawing on industries like steel manufacturing, digital cameras, and encyclopedia publishing, Spackman differentiated between sustaining innovations, adequately addressed through normal processes, and disruptive innovations, where conventional wisdom and structures lead to bad decisions. Several library-world innovations were assessed for disruptive potential, including the Internet, ebooks, and open access, with mixed results.

To meet the challenge of disruptive innovations, libraries must understand their users' "job to be done." Libraries must also learn from nonusers and those who would accept lower quality if it came with greater convenience, since this is where disruption is typically born.

Traditional structures and processes nurture sustaining innovations but stifle disruptive innovation. Management behavior is guided by standards and metrics, which encourage "me-too" innovation. Disruptive innovations do not fit established worldviews and seem illegitimate. They can only be fostered in a unit that is sheltered from the decision-making processes of the parent organization.

Innovative organizations require leaders who set challenges rather than make deci- 
sions; who remove organizational barriers and provide resources, like uninterrupted time; and who don't make people ask permission to experiment or ask for forgiveness if they fail.

By definition, evolution involves death, and libraries may experience painful changes, but the presentation ended on a hopeful note, with reasons to bet on libraries, including the fact that libraries are fragmented but collaborative, and librarians are by nature acquisitive-adopters and adapters.-Andy Spackman, Brigham

Young University, andyspackman@ byu.edu

\section{Mindful in Orlando}

Coming on the heels of their recently published book The Mindful Librarian: Connecting the Practice of Mind-

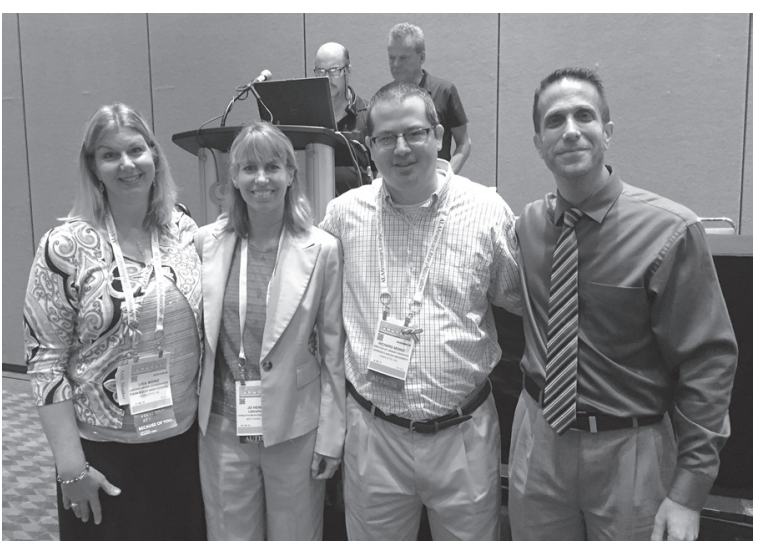

fulness to Librari- "The Mindful Librarian" presenters (left to right): Lisa Moniz, anship, authors Jo Henry, Richard Moniz, and Howard Slutzky.

Richard Moniz,

Lisa Moniz, Jo Henry, and Howard Slutzky conducted a presentation entitled "The Mindful Librarian: Bringing Mindfulness to the Academic Library." With a variety of backgrounds and experiences ranging from academic library administration to clinical psychology, this diverse group led an equally diverse presentation. The session began by sharing the personal reasons why each got involved in the book project and how mindfulness has helped them in their own personal ways.

The presentation had essentially three main parts that were interwoven. One part consisted of engaging in actual mindful practice. This entailed a breathing meditation at the beginning led by Richard Moniz and a visualization meditation at the end led by Slutzky.

Another component of the presentation involved sharing data about librarians' exposure to and involvement with mindfulness and information about library stressors. This information was based on a survey the authors conducted after the publication of their book and contained responses from 629 librarians.

The third component of the session involved sharing some of the content of their book and how mindfulness and librarianship were tied together in specific capacities. For example, Richard Moniz shared how mindfulness is being increasingly adopted in education and how many mindful tenets can relate very directly to reference work, specifically RUSA's Guidelines for Behavioral Performance of Reference and Information Service Providers. Lisa Moniz covered some of the basic concepts put forth by mindfulness guru Jon Kabbat-Zinn and how they may be applied in solo librarian situations or other difficult situations in librarianship. Henry shared insights and studies related to mindfulness as it applies to building relationships with faculty and leading libraries.

The crowd seemed especially appreciative of the opportunity to not just hear but practice mindfulness, as well._Richard Moniz, Johnson \& Wales University, richard.moniz@ jwu.edu

\section{Practical instructional design}

Sponsored by ACRL and presented by Kim Hoffman (University of Rochester), Michelle Costello (SUNY-Geneseo), and Brandon West (SUNYGeneseo), "Practical Instructional Design: Diverse Perspectives in Academic Librarianship" introduced instructional design (ID) strategies and principles that library professionals from all departments could put to good use. 
Session attendees were greeted by small slips of paper asking their personal definition of ID. Several individuals shared their definitions with everyone in attendance, and the presenters followed with their own definition: "intentional, sound instructional or programmatic creation, delivery, and assessment." The presenters went on to state this process "takes into account the audience, course or program context, and shared learning goals."

With this definition in mind, attendees were shown three ID case studies. These case studies were all very different from one another in terms of their scope and focus, and they all showcased different approaches tal to the ID process, including: Who are the stakeholders? and What assumptions do you make about information that is missing?

The activity was a refreshing opportunity to put some of the knowledge learned to practice, and it succeeded in punctuating a very informative and engaging presentation._Daniel Ross, SUNY-Geneseo, rossd@ geneseo.edu

\section{Strengthening relationships and experiences with students}

ACRL and the ACRL Student Retention Discussion Group sponsored a panel on "Strengthening Relationships and Experiences with Students

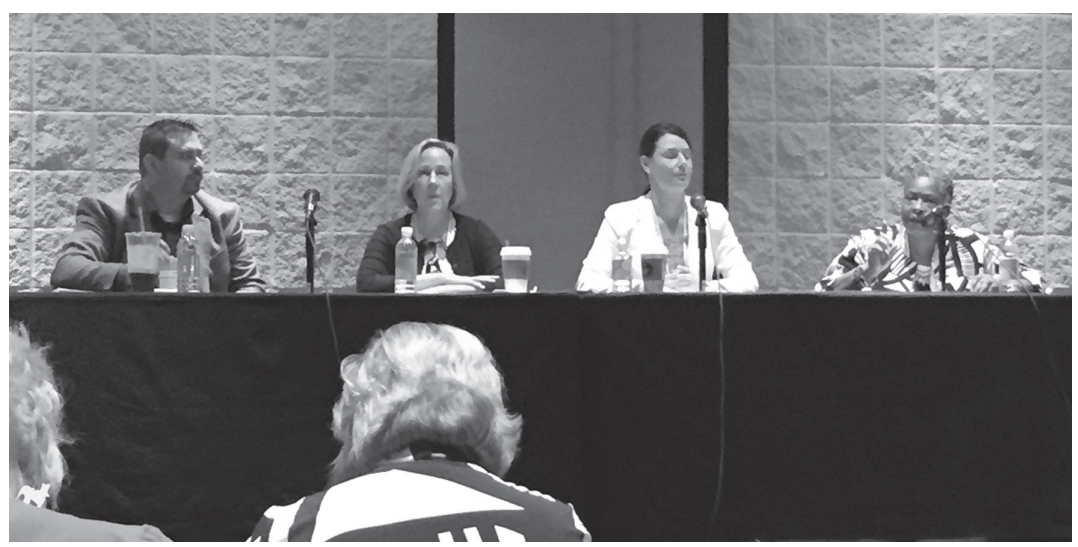

"Strengthening Relationships and Experiences with Students through Personal Librarian Programs" presenters (left to right): Brian C. Gray, Lynne Bisko, Heather Buchansky, and E. Gail Reese.

to ID. This served to drive home the idea that ID can never be uniformly applied in all situations, a key takeaway for attendees.

For example, one case study showed application of the ADDIE model to the creation of online video tutorials, while another case study showed use of the Jerrold Kemp model toward the creation of a student film festival. The situations and models used were different, but both case studies shared an underlying focus on assessment, engagement, audience, and learning objectives.

The session concluded with an activity where attendees were asked to choose one of three scenarios and discuss them with a neighbor by answering questions fundamen- th rou g h Personal Librarian Programs." Three libraries shared their creation, 1ogistics, and assessment strategies.

E. Gail Reese (Case We s t e r n Res e r ve University) defined the major goal of "personal librarian" programs as the creation of relationships to proactively reduce the fear of approaching librarians when a future information need develops. A summary of characteristics showed the extreme variety among the programs, including student count $(1,200$ to more than 5,000$)$ and students included (first-year, transfer, or specific disciplines). Collaborations were customized through partnerships with first-year seminars, residence halls, and subject departments.

Lynne Bisko (Elon University) shared that 16 librarians support the first-year seminar classes. Visibility and goodwill was developed through class visits, emails, and LibGuides. Assessment mechanisms included statistics (8 
to $12 \%$ interaction rate) and student surveys.

Brian C. Gray (Case Western Reserve University) said his library's goal was to increase student retention by helping students become embedded in the culture of the university. There are 34 exempt, full-time personal librarians, and each is assigned a floor in the first-year residence halls. By collaborating with resident assistants, relationships are grown through social and educational activities. Interaction rates and survey results were similar to Elon University's.

Heather Buchansky (University of Toronto) explained how their librarians are serving a very large audience (more than $5,000)$ through various email efforts, meetand-greet opportunities, and promotions. Assessment strategies included coding email interactions, click through rates of emails, and student survey comments.

The 13 total years of experience among the three organizations demonstrated the efforts of each individual librarian were minimal, student ratings were positive, not all students participated, and, through various adaptations, personal librarians programs are very scalable.-Brian C. Gray, Case Western Reserve University, bcg8@case.edu

\section{To surveys and beyond}

"To Surveys and Beyond: Strategies for Assessing Large-Scale Outreach Events" was presented by Elizabeth German, Stephanie Graves, Sarah LeMire, and Chance Medlin (all from the Texas A\&M Libraries). This group of librarians walked the audience through their assessment process and demonstrated why assessment is so important. The overall session was informative, and the information presented was useful and reproducible a library of any size.

The presenters encouraged all who were interested in assessing often nebulous outreach events to make sure to begin with a firm foundation. First define what outreach means for your library. You cannot assess what you have not defined. For Texas A\&M, libraries outreach is "any event or activity that has a distinct user population where you are promoting library services." Once defined, use a mix of qualitative and quantitative methodologies to assess programs. Libraries often dismiss anecdotal evidence, when instead they should pair anecdotal evidence with other forms of assessment and use them together to tell their stories.

Assessment can be as easy as tracking attendance or counting merchandise given out or as difficult as blind surveys and focus groups. The methodology has to fit the event and particular audience, so be thoughtful and do not seek a one-size-fits-all assessment strategy. Assessment can be difficult, but just because it is difficult does not mean it is not worth it. Assessment will allow libraries to more easily demonstrate value, share their stories, and track what actually creates connection to the library.-Dustin Fife, Utah Valley University Library, dustin.fife@uvu.edu.

\section{Authority is constructed and contextual}

Five librarians from different academic libraries across the country argued that traditional notions of what can be construed as "authority" no longer held as much sway as in the past, in the Instruction Section program "Authority is Constructed and Contextual: A Critical View."

The panel included Nicole Pagowsky (University of Arizona), Kevin Seeber (Auraria Library), Dave Ellenwood (University of Washington-Bothell and Cascadia College), James Elmborg (University of Iowa), and Yasmin Sokkar-Harker (CUNY-School of Law).

Seeber said proper communication with faculty and instructors is key for leading an informative and useful session, and librarians can use their expertise and authority to help have that conversation.

Pagowsky said it was important that librarians not forget the value of their authority in leading meaningful education. She also said it was important for librarians to help students to be critical—not just of articles and authors, but of the scholarly process, in general.

Ellenwood championed the importance of looking at the epistemology of learning 
and said that he felt deconstructing authority with students could be both "joyful and scary" for them.

Elmborg, who is an instructor in a library and information science program, said he liked to change students' conceptions of his role as the "authority" in the classroom, asking them to question what gave instructors that authority.

Sokkar-Harker said her role as a law librarian meant her approach was (by necessity) different, but authority was equally or more important to the research of students in law school. "The authority they work with is authority with a capital A," she said.-Jeremiah Paschke-Wood, University of Arizona, jpaschkewood@email.arizona.edu

\section{Open peer review is all about community}

One of the best things about ACRL sessions at the ALA Annual Conference is leaving with solutions to your problems. "Peeling Back the Layers of Publishing Opacity: Open Editorial and Peer Review," sponsored by the ACRL Publications Coordinating Committee and Research and Scholarly Environment Committee, delivered insight as well as a list of tools for increasing your involvement in open peer review. The biggest takeaway from all three speakers was the principle that open peer review helps to build and strengthen communities.

Cesar Berrios-Otero (F1000) discussed the benefits of the open and public discussion that happens when authors post their work to F1000, and how that reduces bias among referees and within the community itself. Karen Estlund (Penn State University Libraries) spoke about the open review process for Ada: A Journal of Gender, New Media, and Technology, which includes peer review editing parties where reviewers learn from one another. Matthew Gold (CUNY Graduate Center) talked about how building community around a text also builds an audience for the author.

Some of the tools and services discussed were F1000Research for publishing scholar- ship (http://f1000research.com/), Manifold for building interactive monographs (http:// manifold.umn.edu/), and Ada: A Journal of Gender, New Media, and Technology (http:// adanewmedia.org).

Post-panel discussion focused again on the theme of building community, as well as the scalability of the various projects and tools mentioned. Ultimately, it became evident that open peer review is, as mentioned by Gold, part of a longer open access trajectory — something that all librarians are working toward.-Amy Buckland, University of Chicago, amybuckland@uchicago. $e d u$

\section{Documenting \#BlackLivesMatter}

Because protest movements with physical and virtual presences are here to stay, the ACRL Rare Books \& Manuscripts Section, ALCTS PARS Digital Preservation Interest Group, and ALA Committee on Diversity organized "\#BlackLivesMatter: Documenting a Digital Protest Movement."

Meredith Evans (Jimmy Carter Presidential Library and Museum) opened the panel with a reminder that librarians have a professional responsibility to preserve a scholarly record that includes all parts of the communities we serve, suggesting the audience "be proactive, not passive-aggressive."

Makiba Foster (then at Washington University in St. Louis), emphasized the importance of using your library's resources to better its surrounding communities. She shared her story of creating a viral Facebook post before her university allowed her to create a LibGuide with information on policing and community protest after Michael Brown's death, which ultimately led to the creation of "Documenting Ferguson," an online Omeka archive that still solicits content that is freely available to all.

Charlton McIlwain (New York University) expanded the conversation by discussing his research on the growth and importance of the BlackLivesMatter hashtag, including the process of buying a primary source data set-more than 40 million tweets—and find- 
ing ways to ensure social media users' privacy by only focusing on top tweeters.

Jarrett Drake (Princeton University) concluded the panel by forcing the audience to confront their complicity in white supremacy when seeking to help community archives. After helping the People's Archive of Police Violence in Cleveland collect oral histories, Drake emphasized building trust. If adding \#BlackLivesMatter material to your institution's collection, he suggests doing so "critically and anti-oppressively," and make sure they already matter in existing collections.Colleen Barrett, Philadelphia Rare Books \& Manuscripts Co., colleen@prbm.com

\section{Collections at the crossroads}

The Resources for College Libraries (RCL) Editorial Board sponsored the panel "Collections at the Crossroads: Revising and Reenvisioning the Core Subject Collection." The panel marked the tenth anniversary of RCL's publication and brought together a range of perspectives on how a core subject bibliography fits into evolving library collection trends.

Anne Doherty (RCL project editor) opened the panel. She outlined the scope of the RCL database and its uses for both collection management and research/instruction. RCL's curated and peer-reviewed list of more than 85,000 core titles functions as an acquisitions aid and qualitative assessment benchmark, and it can be used by librarians to support both new curricular programs and to strengthen subject knowledge.

Mark Emmons (University of New Mexico) outlined collection trends in research libraries, such as reduced mediation and a focus on use rather than preserving the cultural record. He identified theoretical and practical issues with core collections, including the politics of canon, the impact of approval plans, and meeting the needs of unique users at any given institution. As the long-time RCL subject editor for Film Studies, Emmons asserted the benefits of mediated subject expertise to complement approval plans.

Chisato Uyeki (Mt. San Antonio College) offered a contrast to the research library from her vantage point at California's largest single-campus community college. She enumerated five criteria for any relatively small core collection at a two-year institution, such as works that are foundational and classics or geared toward lower-division and introductory courses. Uyeki shared ways that her college's liaison librarians use RCL to maintain a core collection (e.g., in weeding decisions).

Questions and discussion focused on shared core collections, core collections informed by state and other local criteria such as "basic skills" resources at two-year colleges, and more.-Neal Baker, Earlham College, bakerne@earlham.edu

\section{Subject librarians facilitate data services}

Partnerships and pilot programs were the key focus of "Data to Discourse: Subject Liaisons as Leaders in the Data Landscape," sponsored by the Science and Technology Section.

Shannon Farrell (University of Minnesota [UMN]) detailed UMN's data services offerings, including a month-long data management workshop and a second five-day program. Other data services included visits to classes, seminars, lab and faculty meetings, plus integration into orientations and consultations. Farrell also reported on successful partnerships with faculty as part of the pilot DRUM data curation project. She concluded with an overview of the Task Force on Librarians' Competencies for Research Data Management, citing the importance of practicing (writing data management plans, keeping a code book, etc.) in order to cement skills.

Jessica Ritchie (Yale University) focused on the YODA (Yale Open Data Access) project, whose goal is to facilitate access to clinical trial data in order to inform patients, clinicians, and industry, while promoting responsible conduct by researchers and protecting the rights of participants. She described the work so far and the results to date: 165 trials are currently available for sharing, with 46 requests for data use already received. Ritchie concluded with a list of challenges ahead, including methods 
of further engaging the research community, maintaining public input, and consideration of a fee-based system.

Unavailable to speak in person, Daniel R. Shanahan's (BioMed Central) audio presentation addressed key issues related to semantic linking of data with articles. Building from a core question, "Can we trust the published literature?," Shanahan took the perspective that the questions asked, and the processes used, are the core values of research, not necessarily the outcome. One then begins to evaluate research by methods used-to do this, one needs access to the data. CrossRef and other technologies in the OpenTrials project support this new linkage model.

Holly Miller (Florida Institute of Technology), a former biochemist, discussed how new interdisciplinary, complex research paradigms are dependent on shared data. Such research is used secondarily in economics, history, and science-based legislative processes._Michael Leach, Cabot Library, Harvard University, mrleach@fas.harvard.edu

\section{Taking our seat at the table}

The University Libraries Section program, "Taking Our Seat at the Table: How Academic Librarians Can Help Shape the Future of Higher Education," focused on positive approaches academic libraries are taking to impact their communities outside traditional boundaries. Maria Martinez-Cosio (University of Texas-Arlington), led with highlights of a grant-funded collaboration in which areas of the library were turned into an after-hours academic plaza containing advising, tutoring, and group study rooms. This project, based on student need, has been very well received.

Monica Metz-Wiseman (University of South Florida [USF] Libraries) spoke about the libraries' leadership in strengthening open electronic resources, particularly textbooks, at USF. Touching on the difficult financial situation that many students find themselves in, Metz-Wiseman covered several different OER initiatives the libraries have developed that have saved USF students more than $\$ 1$ million to date.

Sue Ryan (Stetson University) presented her library's efforts to enhance the university curricula by promoting their 3-D printing lab. Ryan discussed ways in which faculty have incorporated 3-D printing into their assignments with resultant increases in student learning, as well as the wealth of presentations and publications faculty have produced as a result of their collaboration with the library.

Rounding out the panel, Catherine MurrayRust (Georgia Institute of Technology) urged librarians to involve themselves on their campuses by becoming contributors and influencers. She listed ideas for involvement and said, "If this sounds like dating advice, some of the same principles apply." Murray-Rust concluded that librarians need to develop a strategy and be intentional about putting themselves forward in order to be seen as professionals who can contribute outside traditional library boundaries.-Anne Marie Casey, Embry-Riddle Aeronautical University, caseya3@erau.edu $\mathbf{n}$

("Participatory archiving," continues from page 379)

\section{Notes}

1. "Mass. Memories Road Show," accessed March 25, 2016, http://openarchives. umb.edu/cdm/landingpage/collection/ p15774coll6.

2. "Common Heritage," National Endowment for the Humanities, accessed March 25, 2016, www.neh.gov/grants/preservation/ common-heritage.

3. Tamara Chuang, "Mailbag: Best Way to Archive Old Photos? An Expert has a Surprising Suggestion," The Denver Post, March 16, 2015, accessed March 25, 2016, www. denverpost.com/business/ci_27707891/bestway-archive-old-photos-an-expert-has.

4. Obviously, a participating repository would need a digital asset management system (DAMS) to make the collections available

(continues on page 410) 